\title{
A test for solid phase extracted polychlorinated biphenyls (PCBs) levels in transformer oil
}

\author{
E. A. Kamba, A. U. Itodo, E. Ogah \\ Department of Chemical Sciences, Federal University Wukari, Nigeria.
}

Email address:

eacambah@yahoo.com (E. A. Kamba), itodoson2002@gmail.com (A. U. Itodo)

\section{To cite this article:}

E. A. Kamba, A. U. Itodo, E. Ogah. A Test for Solid Phase Extracted Polychlorinated Biphenyls (PCBs) Levels in Transformer Oil, American Journal of Electrical Power and Energy. Systems. Vol. 2, No. 3, 2013, pp.57-65. doi: 10.11648/j.epes.20130203.11

\begin{abstract}
Polychlorinated biphenyls (PCBs), the synthetic electrical insulation fluid in transformers and capacitors, known to reduce the risk of fire hazards due to their high chemical stability and low flammability turned out to be environmentally hazardous. In this research, different techniques used to analyses Polychlorinated biphenyls (PCBs) in transformer oil including their qualification and identification processes have been outlined. 12 samples of transformer oils collected from various transformers from Kebbi state, Nigeria were investigated. Solid Phase Extraction (SPE) method was used to treat the oil samples and extracts were analyzed on Gas Chromatography with Electron Capture Detection (GC/ECD). No detectable PCBs were observed. To check the efficiency the SPE tubes, oil sample A10 was spiked with Mix 525 of PCB standard and treated. A full recovery of all the PCBs of Mix 525 was made even at a level as low as 50ng/ul with GC/MS. The results obtained in this study confirm that transformer oil from Kebbi state is well within the safe level of PCBs in accordance with EPA PCB Regulatory limited.
\end{abstract}

Keywords: Kebbi State, Transformer Oil, Polychlorinated Biphenyls, GC/MS, GC/ECD, Solid Phase Extraction

\section{Introduction}

Polychlorinated biphenyls (PCBs) are a group of organic compounds in which about 1-10 hydrogen atoms of biphenyl are replaced by chlorine atoms [1]. There are 209 distinct PCB compounds (known as congeners) each of which consists of a biphenyl molecule with a specific number of chlorine atoms attached[1]. PCBs have a general chemical formula of $\mathrm{C}_{12} \mathrm{H}_{10-\mathrm{x}} \mathrm{CI}_{\mathrm{x}}$ (the $\mathrm{x}$ represents the 1-10 hydrogen atoms that can be replaced with chlorine atoms) [2][3][4]. PCBs were widely used as a dielectric fluid in electrical transformers and capacitors [4][5]. It was discovered in the 1930 s, that transformers and capacitors needed a synthetic electrical insulation fluid to reduce the risk of fire hazards. This led to the production of PCBs which proved to have some performance and electrical strength to resist fire, and as expressed by electrical engineers "it enabled the transformers to be positioned anywhere" [6].

Due to their high chemical stability and low flammability and some other desirable physical properties, their commercial utility increased [2]. Unfortunately, PCBs turned out to be environmentally hazardous which led to the banning of their production [7].

PCBs are classified as Persistent Organic Pollutants
(POP), which when in contact with the environment are not easily degradable [8][5]. PCBs find their way into the environment mainly through industrial processes, urban incineration, improper disposal; practices, re-use of incompletely reconditioned oil and hazardous waste accidents; a large amount is also believed to have leaked out of transformers into the environment unintentionally, [9][10][5][3]. Previously PCBs were referred to as just 'Phenyls' or by different trade names such as Aroclor, Kennechlor, Pyrenol etc.

\subsection{Chemistry of PCBs}

Benzene is a very stable compound, but heating it to a very high temperature can cause disruption of the Carbon-hydrogen bonds[7]. In the presence of a catalyst biphenyl is obtained (figure 1), which itself is a molecule with two benzene rings linked by a single bond between the carbon atoms which have lost an atom of hydrogen each. [11] 


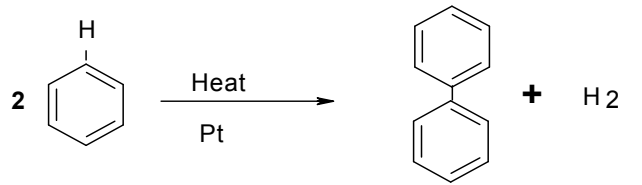

Figure 1: Reaction between two benzene rings to give biphenyl

If biphenyl is combined with chlorine in the presence of a ferric chloride as catalyst, like benzene, depending on the number of chlorine atoms introduced, hydrogen atoms are displace. The products obtained are referred to as polychlorinated biphenyls (PCBs)[12]. The number and position of the chlorine atoms on the biphenyl molecule determine the congener's nomenclature as well as dictate its environmental fate and toxicity. The more chlorinated congeners are generally the most persistent and toxic [1].

When numbering an individual PCB congener, certain rule is followed. It starts with the carbon of one ring that is joined to a carbon of the other ring, given the first number 1, and other the carbons of the ring are given the other numbers (2-6).

However, the number in the second ring is distinguished by adding a prime to the numbers (figure 2). The second position in the second ring lies on the same side of the carbon-carbon bond that joins the rings as the second position in the first ring. The same applies to the other positions [12].

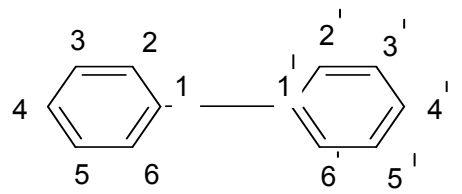

Figure 2: Positions of Carbon atoms of biphenyl

The two rings Chlorinated biphenyl molecule are used not equivalent as the patterns of substitution differ. The ring with unprimed numbers is chosen to give a substituent with the lowest carbon number (Figure 3). [12]

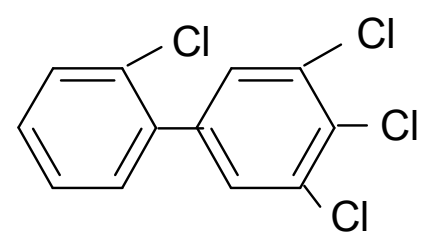

Figure 3: 2, 3', 4', and 5'-tetrachlorobiphenyl

There tends to be a quick rotation around carbon-carbon single bonds in most organic molecules. This includes the carbon-carbon link between the two rings of biphenyls, and indeed to most PCBs [12]. It is usually not possible to isolate compounds that correspond to different orientations of the two rings in PCB relative to each other. For instance, 3, 3'-and 3,5'-dichlorobiphenyl are not individual isolatable compounds; one form is constantly being converted into the other and back again by rapid rotation about the carbon-carbon bond joining the rings figure 4)[12]

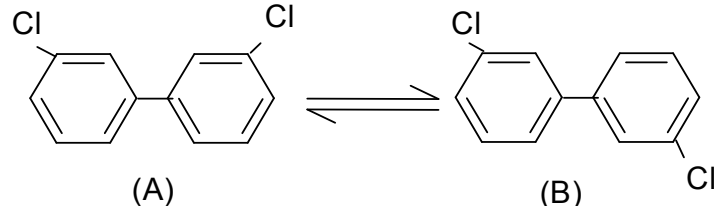

Figure 4: (A)3,3'-dichlorobiphenyl.(B)3,5'-dichlorobiphenyl

Several attempts to identify particular plants as a source of PCBs contamination have proved abortive; however, the only reliable means of achieving this has been through chemical analysis of oils used in plants [13]. There are several ways of determining the presences of PCBs in electrical insulating oils. Two of such ways are:

The used of enzyme immunoassays[13] and iconography-high resolution mass spectrometry[14]. Impurities in transformer oil need to be removed before effective determination of PCBs can be carried out[15]

PCB analysis is divided into two categories; specific and non-specific methods[16]. The specific methods particular test for PCB molecules while the non-specified methods identify the classes of compounds (e.g. chlorinated hydrocarbons) to which PCBs belong[16]. Specific method includes gas chromatography (GC) and mass spectrometry (MS). None-specific methods include Choir-N-Oil PCB screening kits, $\mathrm{x}$-ray fluorescence spectrometry, microcoulemetric titration, and total organic halogen (TOX) test[16].

Generally, PCB analysis is performed with such analytical equipment as packed-column Gas Chromatography coupled with Electron Capture Detector (GC-ECD), capillary-column GC-ECD, quadrupled low-resolution Gas chromatography/mass spectrometry (GC/MS)[18][15] and double-focus high-resolution GC/MS[18][17]. An electron capture detector can detect any chlorinated compound including PCBs, when a GC is used to separate the components of the mixture (oil sample).

Takada, et al, in 2001 observed that efficient and cost-effectiveness of PCB analysis can be improved if the dimethylsulfoxide (DMSO) portionsolid phase extraction (SPE) were used in the clean-up of the PCB contaminated transformer oils. They used quadrupole GC/MS to determine PCB level in transformer oil and the analytical data were compared with those of the standard method using statistics.

A suitable solvent was added to the sample containing PCB to be analyzed to dilute it, which was then treated to remove substances (impunities) that may otherwise alter the determination process. The treated sample solution was then analyzed using gas chromatography procedure with an electron capture detector. The result obtained was then evaluated by comparing it with the standard for the PCB sources known[15]. The data collected can be used to identify the type of PCB or their mixtures and their quantity in the sample. The result obtained are usually reported in parts per million (ppm), of the PCB present[19] 
Table 1: Classification of electrical equipment and insulating fluids according to the level of $P C B$ contamination

\begin{tabular}{ll}
\hline PCB Concentration (ppm) & Classification \\
\hline Less than 50 & Uncontaminated equipment \\
Greater than 50, less than 500 & PCB contaminated equipment/fluid \\
Greater than 500 & PCB equipment/fluid \\
\hline
\end{tabular}

Source: (NTT, 1999)

The overwhelming release of PCBs into environment posed a serious danger owing to their persistency and toxicity. The hydrophobicity of PCBs causes them to bio accumulate in the fatty issues of organisms, hence, their toxicity[20][8][3] the amount and concentration of PCBs in an organism determines the extent of damage caused to the organism exposed to them[8]. Although the actual extent of damage in human is still not certain, it appeared the PCBs do not immediately exhibit significant hazards upon exposure to them[8][21]. However, they cause effects on the neurological and immunological systems, liver and thyroid gland[8][2].Other effects caused by PCBs include Chloracne, which is another form of acne and is common to people who are exposed to organochlorine compounds for a long period of time[12]. [22] reported that "taken as a whole, the prepondence of evidence appears to support the argument that PCBs constitute a minimum threat to human health. Action phasing out their use is justified based on their capacity to accumulate in the environment"

Table 2: Average concentrations of organochlorine

\begin{tabular}{lllll}
\hline \multicolumn{1}{c}{ Matrix Dimension } & PCB & HCH & HCB & DDT \\
\hline Air ng/M & & & \\
Snow ng/L & 0.014 & 0.58 & 0.19 & $<0.001$ \\
Seawater (surf.) ng/L & 0.086 & 1.72 & $<0.002$ & $<0.01$ \\
Seawater (deep ) ng/1 & $<0.014$ & 0.51 & 0.01 & $<0.002$ \\
Zooplankton ug/g lipid & 0.11 & 0.08 & 0.02 & 0.06 \\
Amphipods ug/g Lipid & $<0.44$ & 0.5 & 0.17 & $<0.35$ \\
Cod ug/g lipid & 0.23 & 0.58 & 0.2 & 0.26 \\
Belugaug/g lipid & 3.79 & 025 & 0.5 & 2.82 \\
Ringed seal ug/g lipid & 055 & 0.23 & 0.03 & 0.5 \\
Polar bear ug/g lipid & 5.4 & 0.51 & 0.27 & 0.4 \\
Human milk ug/g lipid & 1.05 & $\mathrm{NA}$ & 0.14 & 1.21 \\
\hline
\end{tabular}

Sourve: [9]

\subsection{Distribution of PCBs}

It is a common belief these days that many chlorinated organic compounds including PCBs are distributed globally through the atmosphere[9][10][23]. The distribution occurs mainly by a phenomenon in which substances evaporate and spread to the atmosphere at latitudes with warmer climates and then condense and fall- out closer to the poles. As a result, regions near to the Northern and Southern Poles receive a disproportionate share of this fall-out[9]. PCBs and some other polychlorinated compounds were detected in marine organisms, lakes and sea sediments in remote areas such as the Arctic and the Antarctic [9].

Table 2 below shows average concentrations of polychlorinated biphenyls (PCBs) hexachlorohexanes (HCHs), hexachlorobenzene (HCB), dichlorodiphenylchoroethene (DDT) and chlordane[9].These result were obtained from experiments carried out in Arctic environment which show variation in concentration against experimental results obtained in the Antarctica [9].

About 94,800 kg of PCBs was estimated discharged into Hudson River by general electric company from two capacitor manufacturing plants located in Hudson falls, New York [2]. Anextensive toxic waste problem has been created ever since owing to the PCBs spread throughout the river and its food chain. This led to banning of fishing in the river by the New York state[2]. In Africa a worse scenario is expected as the wide distribution of PCB containing equipment, the poor storage of PCB-contaminated oils and the high cost of incineration make it likely that there will be further releases of PCBs to the (global) environment [24][25]. In the UK the sale and new usage of PCBs was prohibited in 1986, although a part of it is still encountered in some part of the country due to the fact that not every electrical unit have been refilled with PCB-free insulating oils [13]. There has been a significant reduction of the use of PCBs in the UK between 1990 and 1998 (table 3) [26].

Table 3: PCB emissions in the UK for 1990 and 1998

\begin{tabular}{|c|c|c|}
\hline Sources of emissions & $\begin{array}{l}1990 \\
\text { emissions (kg) }\end{array}$ & $\begin{array}{l}1998 \\
\text { emissions }(\mathrm{kg})\end{array}$ \\
\hline Electrical equipments & 6,228 & 2,193 \\
\hline Application of sewage sludge & 70 & 33 \\
\hline Power stations & 89 & 44 \\
\hline Industrial/domestic combustion & 32 & 22 \\
\hline Iron and steel industry & 529 & 441 \\
\hline Other sources & 28 & 14 \\
\hline Total & 6,976 & 2,747 \\
\hline
\end{tabular}

Source:UK national atmospheric emissions inventory (in weight, 2003)

This work is not aimed at comparing methods but to understand the various techniques use in determining the presence, quantifying the amount and identifying the type of PCBs in transformer oils and to Identify transformers capable of releasing harmful PCB containing fluids into the environment.

\section{Materials and Methods}

\subsection{Sample Collection /Inventory of Transformers}

Twenty two samples of transformer oils from various 
areas were collected randomly by power Holding Company of Nigeria (PHCN) in Kebbi State. The collection or sampling activities were conducted in accordance with procedure presented in the sampling method by Shin, et. al; 2004 (that is the Ministry of environment in Korea, Korean Waste Official method, 2004). Prior to sampling the transformer oils, the power was disconnected by electricians at the working region. An inventory of the transformers from which the sample was collected was taken. The transformer valves were opened and $60 \mathrm{ml}$ oil samples collected in polypropylene bottles. The containers were filled to the top and then the transformer valves were closed carefully and the container caps tightly fitted unto the containers. Finally the containers were labeled and samples were transported to the laboratory at the University of Greenwich in the UK and stored at room temperature

\subsection{Oil Pre-treatment:Solid Phase Extraction (SPE) Method.}

In this study Solid Phase Extraction Method (SPE) for polychlorinated biphenyls (PCBs) cleanup was used Supelco's Application Note 67 Solid" Phase Extraction of PCBs from Transformer Oil and Waste Oil, and Analysis by Capillary GC" (Supelco's Bellefonte, USA). This procedure was chosen because of its significant advantages which include; avoiding the use of concentrated sulphuric acid, less need for glass wares, reducing solvent costs and disposal problems, it is faster than the acid extraction method, and many samples can be processed simultaneously on the SPE vacuum manifold

A $500 \mu \mathrm{L}$ aliquot of isooctane $(2,2,4$-Trimethlpentane) was added to a Supelelclean ${ }^{\mathrm{TM}}$ LC-Florisil $^{\circledR}$ solid phase extraction tube (Supelco). 0.2g of transformer oil sample was added onto the frit. PCB was flushed through the tube by adding five $2 \mathrm{ml}$ aliquots of isooctane. The eluant was collected in a glass vial. This was repeated for all the 12 transformer oil samples using a new SPE tube for each sample

\subsection{Chromatographic Operating Conditions}

The collected eluant was analyzed using Agilent 6890 GC coupled with an Electron Capture Detector (ECD) and connected to a PC with EZChrom Elite software. A DB5 GC Column; $30 \times 0.25 \mu$ p internal diameter (J \& W Scientific) was used with helium carrier gas for the analysis of the sample eluants. The oven initial temperature was set at $50^{\circ} \mathrm{C}$ for 2 minutes, and then programmed at $8^{\circ} \mathrm{C} \mathrm{min}{ }^{-1}$ to $320^{\circ} \mathrm{C}$. The GC was equipped with a 7683 auto sampler in which all the samples were put and allowed to run automatically. The injector point and the ECD temperature were set at $300^{\circ} \mathrm{C}$.

\subsection{Verification}

Sample A01 was spiked a solution of PCB standard Mix 525 (Catalog No. 48246). Then the same SPE was carried out as was done to the other oil samples. Eluant was collected and run in GC/ECD. In the standard, each PCB is
$500 \mu \mathrm{g} / \mathrm{ml} .100 \mu \mathrm{l}$ of the standard was added to $10 \mathrm{ml}$ of oil to make the concentration of each PCB in the oil $5 \mathrm{ng} / \mu$ l that is $1 / 10$ of the safe level.

Mix 525 was diluted to $50 \mathrm{ng} / \mu \mathrm{l}$. SPE was then carried out and eluant collected and run in GC/MS.

\section{Results and Discussions}

\subsection{Transformer Survey Result}

The transformer inventory results which include information on the types of transformer, serial number, manufacture year, manufacturer and type of commercial dielectric fluids used are presented in Table 4.

Table 4: Transformer inventory/Sampling information

\begin{tabular}{llll}
\hline $\begin{array}{l}\text { Sample } \\
\text { ID }\end{array}$ & Serial No & Man. year & $\begin{array}{l}\text { Commercial } \\
\text { Dielectric } \\
\text { Fluid }\end{array}$ \\
\hline A1 & TP & 1979 & Minel \\
A2 & 7716. 100/48113 & 1991 & $\begin{array}{l}\text { Hawker } \\
\text { Siddeley }\end{array}$ \\
A3 & E81-349 & 1999 & NI \\
A4 & WB 90540 & 1990 & Seoul Korea \\
A5 & A 08233197 & 1981 & Mitsubishi \\
A6 & $02 / 82 / 2370$ & 1983 & ONAN \\
A7 & 10104 & 2001 & ELCO \\
A8 & A 08252556 & 1981 & Mitsubishi \\
A9 & HD $118707 / 4$ & 1977 & Woden \\
A10 & D 1109498 & 1952 & GCE \\
A11 & 37888 & 1991 & NI \\
A12 & 26894 & 1991 & NI \\
\hline
\end{tabular}

Different transformers use different dielectric fluids (as recommended by the manufacturer). Only 2 transformers were made in Japan, 2 in Yugoslavia and 3 in the UK. The number of transformers sample was $10.6 \%$ of the total number of transformers around the Kebbi state capital. The survey results show that both the transformers and the dielectric fluids used in them were imported. Therefore, since transformers oils are the major source of PCB contamination, it could be said that greater percentage of the PCBs presence in Kebbi state were imported to be used as commercial products from Japan, UK and Yugoslavia.

\subsection{Analytical Results}

In the analytical process, PCBs were fist separated from the samples by solid Phase Extraction procedure. This was adopted because analytical techniques which are highly sensitive (such as GC/MS) require pre-treatment of samples of transformer oil to be analyzed in order to separate the PCBs from oil[17].

All the tables showing retention times for the major peaks of all the 12 transformers oil samples obtained from the ECD are presented below. To verify the SPE procedure, sample 
A01 was spiked with $200 \mu$ l of Mix 525 and treated the same way. When the extract was injected into GC/ECD all the PCB peaks contained in Mix 525 did appeared. So it shows that the PCBs (if any) certainly were separated from the oil and did come through SPE tubes.

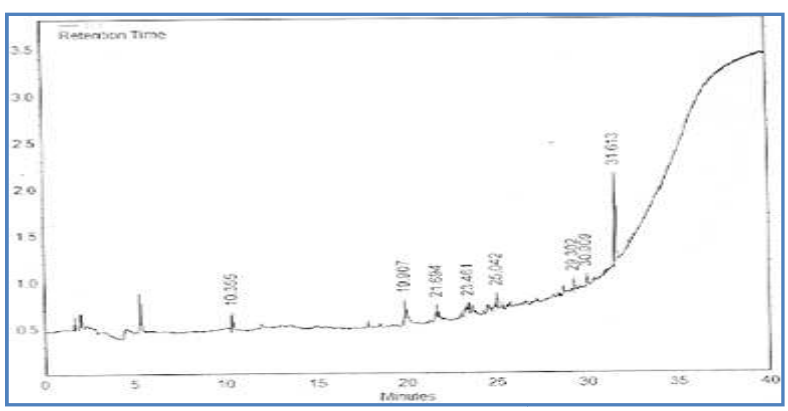

Figure 5: Chromatogram for sample A01

Table 5: Sample ID A01 spiked EDC Results

\begin{tabular}{llll}
\hline Peak No. & Retention Time & Area & Area \% \\
\hline 1 & 19.91 & 2141691 & 25.86 \\
2 & 21.69 & 1061280 & 12.81 \\
3 & 25.04 & 1042343 & 12.59 \\
4 & 31.24 & 56249 & 0.68 \\
5 & 31.61 & 3980245 & 48.06 \\
\hline
\end{tabular}

Table 5 shows retention times, names, areas and percentages of PCBs of spiked sample A01. Note that all the PCBs in the Mix 525 have been recovered. This indication confirms that every step of the procedure have worked through efficiently. Although minor peaks were observed in the chromatograms of the oil samples (which could be PCBs). If these peaks were PCBs, they are probably only about $1 / 100$ of the peaks in the standard and the latter are at $1 / 10$ of the permitted level

Table 6: Summary of peaks information

\begin{tabular}{llllll}
\hline Peak & R/Time & Name & $\begin{array}{l}\text { PCB } \\
\text { No }\end{array}$ & Area & Area \% \\
\hline 1 & 18.38 & a & 1 & 1943059 & 0.67 \\
2 & 21.58 & b & 5 & 26370050 & 9.10 \\
3 & 23.65 & c & 29 & 32422069 & 11.19 \\
4 & 25.15 & d & 47 & 34155209 & 11.79 \\
5 & 26.59 & e & 98 & 4408093 & 11.87 \\
6 & 28.13 & f & 154 & 38552820 & 13.31 \\
7 & 31.22 & g & 171 & 60187586 & 20.77 \\
8 & 31.36 & h & 199 & 59787791 & 20.63 \\
\hline
\end{tabular}

$\mathrm{a}=2$-chlorobiphenl , $\mathrm{b}=2,3$-dichlorobiphenl, $\mathrm{c}=2,4,5$-Trichlorobiphenl, $\mathrm{d}=-2,3$, '4, '4-Tetrachlorobiphenl;e=2,2,4,'6-Pentachlorobiphenl;f=2,2'4,'4 ,'5,6'-Hexachlorobiphenl;g=2,2,'3,3,4,4,6'-Heptachlorobiphenl, ,2,3,3,'4, $5,6,6$ '-octacchlorobiphenl.

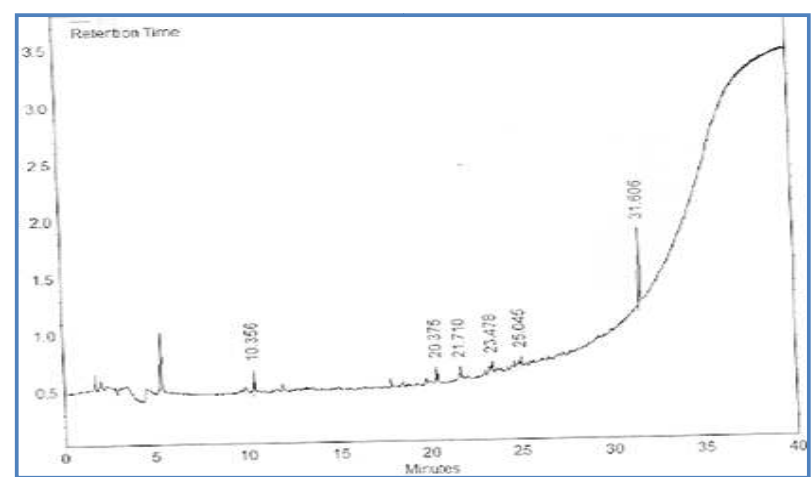

Figure 6: Chromatogram for sample A02

Table 7: Sample ID A02 spiked EDC Results

\begin{tabular}{llll}
\hline Peak No. & Retention Time & Area & Area \% \\
\hline 1 & 31.61 & 2751701 & 100.0 \\
\hline
\end{tabular}

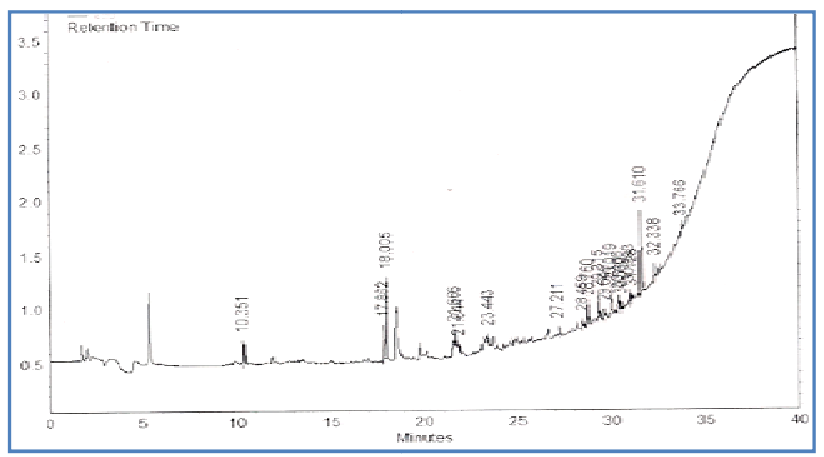

Figure 7: Chromatogram for sample A03

Table 8: Sample ID A03 ECD Results

\begin{tabular}{llll}
\hline Peak No. & Retention Time & Area & Area \% \\
\hline 1 & 5.32 & 3019611 & 15.96 \\
2 & 17.86 & 1465805 & 7.75 \\
3 & 18.01 & 2792218 & 14.76 \\
4 & 18.52 & 5445988 & 28.79 \\
5 & 21.67 & 1513306 & 8.00 \\
6 & 30.02 & 1070652 & 5.66 \\
7 & 31.13 & 264177 & 1.40 \\
8 & 31.24 & 176876 & 0.94 \\
9 & 31.45 & 115198 & 0.61 \\
10 & 31.61 & 3053175 & 16.14 \\
\hline
\end{tabular}

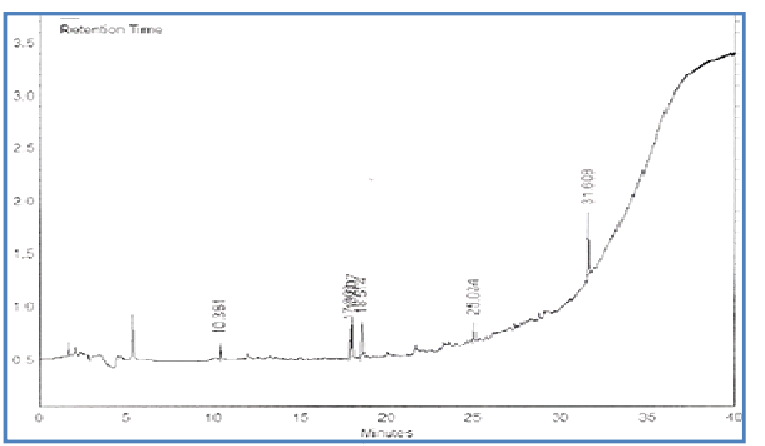

Figure 8: Chromatogram for sample A04 
Table 9: Sample ID A04 spiked EDC Results

\begin{tabular}{llll}
\hline Peak No. & Retention Time & Area & Area \% \\
\hline 1 & 17.86 & 1210893 & 14.89 \\
2 & 18.01 & 1563269 & 19.23 \\
3 & 18.51 & 2664922 & 32.78 \\
4 & 31.61 & 2690762 & 33.10 \\
\hline
\end{tabular}

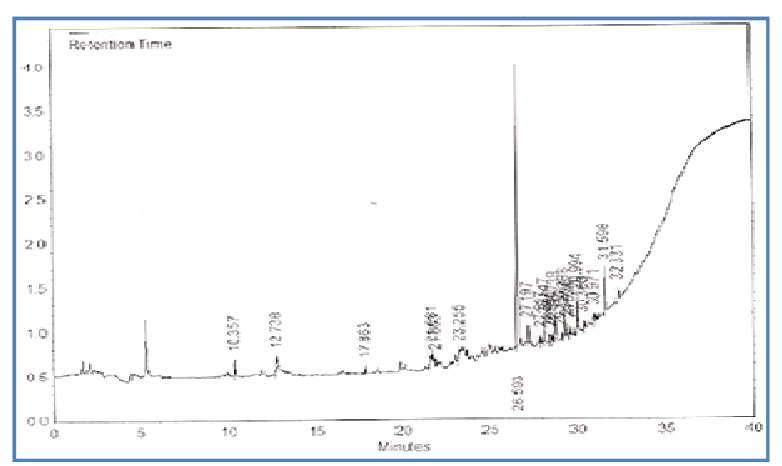

Figure 9: Chromatogram for sample A05

Table 10: Sample ID A05 ECD Results

\begin{tabular}{llll}
\hline $\begin{array}{l}\text { Peak } \\
\text { No. }\end{array}$ & Retention Time & Area & Area \% \\
\hline 1 & 12.74 & 1349960 & 4.32 \\
2 & 21.68 & 1329313 & 4.26 \\
3 & 23.67 & 1242685 & 3.98 \\
4 & 26.59 & 17618101 & 56.42 \\
5 & 27.20 & 1322943 & 4.24 \\
6 & 28.15 & 1116933 & 3.58 \\
7 & 28.74 & 1546409 & 4.95 \\
8 & 29.29 & 1151251 & 3.69 \\
9 & 29.99 & 1790312 & 5.73 \\
10 & 31.11 & 213389 & 0.68 \\
11 & 31.23 & 245924 & 0.79 \\
12 & 31.60 & 2296880 & 7.36 \\
\hline
\end{tabular}

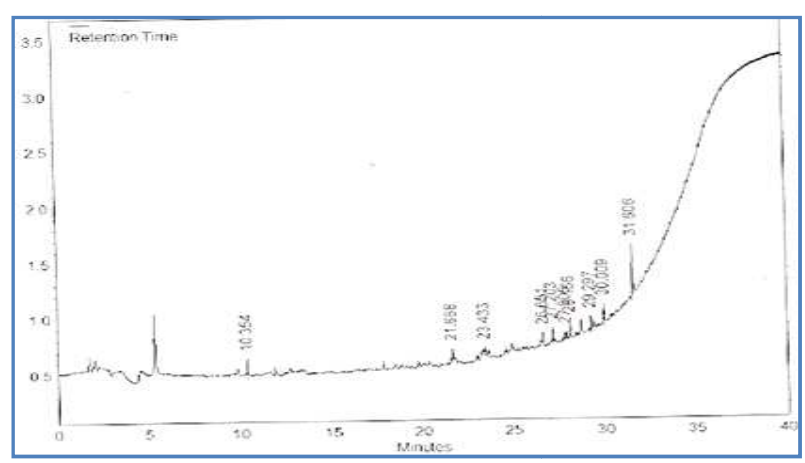

Figure 10: Chromatogram for sample A06

Table 11: Sample ID A06 ECD Results

\begin{tabular}{llll}
\hline Peak No. & $\begin{array}{l}\text { Retention } \\
\text { Time }\end{array}$ & Area & Area \% \\
\hline 1 & 5.34 & 2677290 & 57.86 \\
2 & 31.61 & 1950076 & 42.14 \\
\hline
\end{tabular}

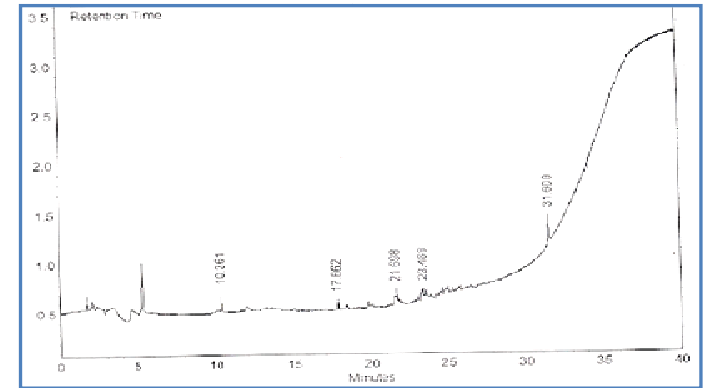

Figure 11: Chromatogram for sample A07

Table 12: Sample ID A07 ECD Results

\begin{tabular}{llll}
\hline Peak No. & Retention Time & Area & Area \% \\
\hline 1 & 21.70 & 1157232 & 47.91 \\
2 & 31.61 & 1258125 & 52.09 \\
\hline
\end{tabular}

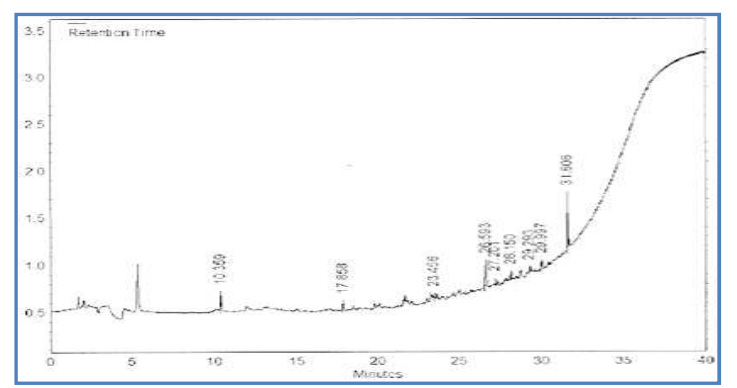

Figure 12: Chromatogram for sample A08

Table13: Sample ID A08 ECD Results

\begin{tabular}{llll}
\hline Peak No. & Retention Time & Area & Area \% \\
\hline 1 & 26.59 & 1096457 & 23.73 \\
2 & 26.60 & 1120362 & 24.25 \\
3 & 31.61 & 2403758 & 52.02 \\
\hline
\end{tabular}

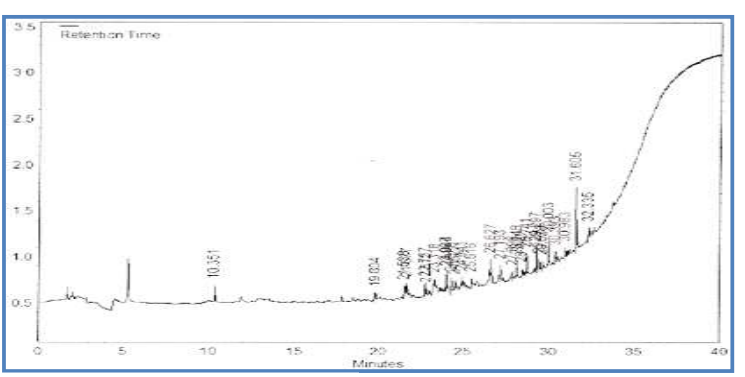

Figure 13: Chromatogram for sample A09

Table 14: Sample ID A09 ECD Results

\begin{tabular}{llll}
\hline Peak No. & $\begin{array}{l}\text { Retention } \\
\text { Time }\end{array}$ & Area & Area \% \\
\hline 1 & 5.32 & 2725811 & 23.88 \\
2 & 23.32 & 1309205 & 11.47 \\
3 & 26.63 & 1698453 & 14.88 \\
4 & 28.74 & 1233489 & 10.81 \\
5 & 30.00 & 1281414 & 11.23 \\
6 & 31.12 & 193556 & 1.70 \\
7 & 31.23 & 215540 & 1.89 \\
8 & 31.61 & 2757781 & 24.16 \\
\hline
\end{tabular}




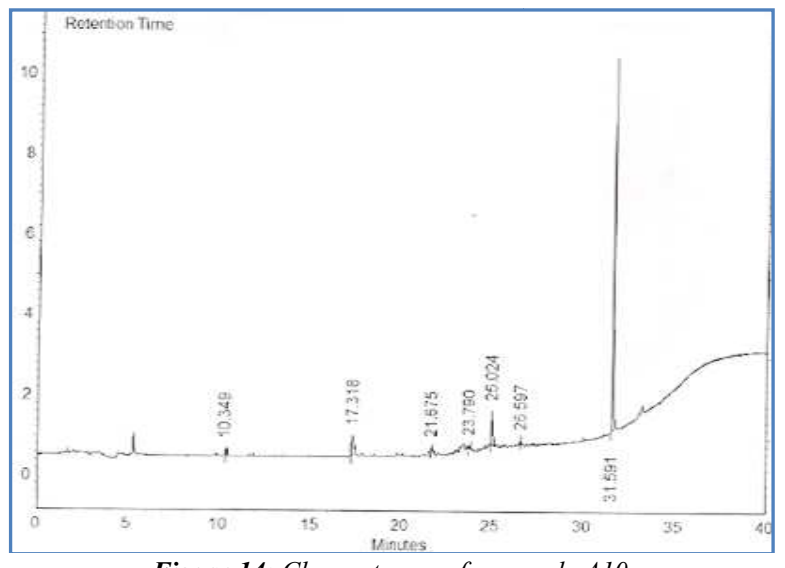

Figure 14: Chromatogram for sample A10

Table 15: Sample ID A10 ECD Results

\begin{tabular}{llll}
\hline $\begin{array}{l}\text { Peak } \\
\text { No. }\end{array}$ & Retention Time & Area & Area \% \\
\hline 1 & 17.32 & 5234234 & 10.66 \\
2 & 21.68 & 1328705 & 2.71 \\
3 & 23.45 & 1250498 & 2.55 \\
4 & 24.65 & 1253454 & 2.55 \\
5 & 25.02 & 4297787 & 8.75 \\
6 & 31.13 & 158364 & 0.32 \\
7 & 31.59 & 35572045 & 72.46 \\
\hline
\end{tabular}

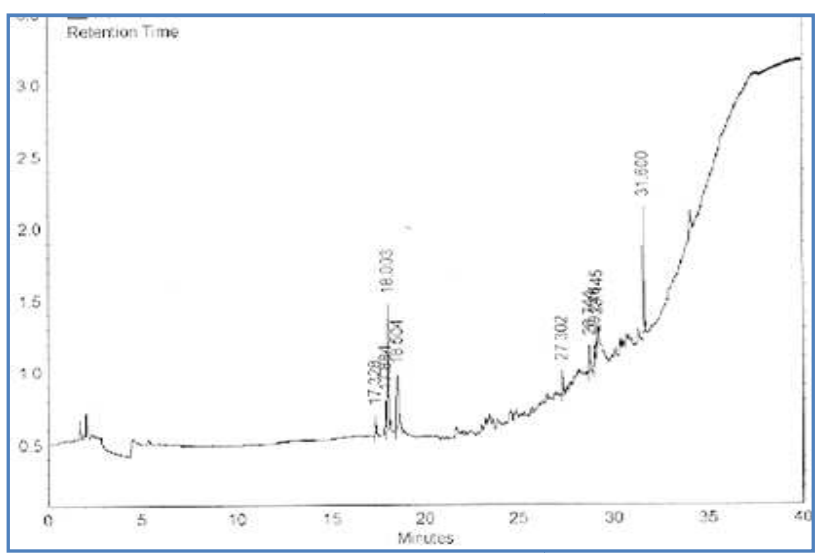

Figure 15: Chromatogram for sample A11

Table 16: Sample ID A11 ECD Results

\begin{tabular}{llll}
\hline Peak No. & $\begin{array}{l}\text { Retention } \\
\text { Time }\end{array}$ & Area & Area \% \\
\hline 1 & 17.88 & 1353579 & 6.49 \\
2 & 18.00 & 4426194 & 21.23 \\
3 & 18.50 & 5049856 & 24.22 \\
4 & 27.30 & 1180478 & 5.66 \\
5 & 28.74 & 1311892 & 6.29 \\
6 & 29.05 & 1227439 & 5.89 \\
7 & 29.15 & 2056201 & 9.86 \\
8 & 31.31 & 418184 & 2.01 \\
9 & 31.35 & 93304 & 0.45 \\
10 & 31.60 & 3733953 & 17.91 \\
\hline
\end{tabular}

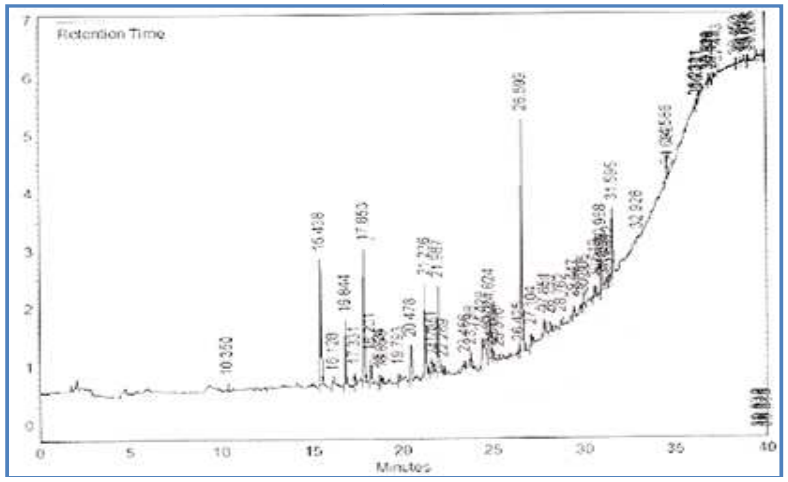

Figure 16: Chromatogram for sample A12

Table 17: Sample ID A12 ECD Results

\begin{tabular}{llll}
\hline $\begin{array}{l}\text { Peak } \\
\text { No. }\end{array}$ & $\begin{array}{l}\text { Retention } \\
\text { Time }\end{array}$ & Area & Area \% \\
\hline 1 & 15.44 & 10564042 & 9.22 \\
2 & 16.84 & 5958207 & 5.20 \\
3 & 17.33 & 1085908 & 0.95 \\
4 & 17.63 & 1122901 & 0.98 \\
5 & 17.85 & 11679157 & 10.20 \\
6 & 18.20 & 2853566 & 2.49 \\
7 & 20.48 & 3337403 & 2.91 \\
8 & 21.24 & 9379817 & 8.19 \\
9 & 21.57 & 2875707 & 2.51 \\
10 & 21.71 & 1366775 & 1.19 \\
11 & 21.99 & 8297043 & 7.24 \\
12 & 22.27 & 1032256 & 0.90 \\
13 & 23.47 & 1025086 & 0.89 \\
14 & 23.71 & 1377927 & 1.20 \\
15 & 23.80 & 1270827 & 1.11 \\
16 & 24.44 & 5247210 & 4.58 \\
17 & 24.82 & 5489181 & 4.79 \\
18 & 25.03 & 1126382 & 0.98 \\
19 & 26.60 & 21548352 & 18.81 \\
20 & 27.10 & 1414019 & 1.23 \\
21 & 27.85 & 1589961 & 1.39 \\
22 & 28.15 & 1590149 & 1.39 \\
23 & 30.62 & 1163440 & 1.02 \\
24 & 30.97 & 3353034 & 2.93 \\
25 & 31.06 & 271510 & 0.24 \\
26 & 31.10 & 92479 & 0.80 \\
27 & 31.16 & 86802 & 0.80 \\
28 & 31.22 & 352128 & 0.31 \\
29 & 31.23 & 202755 & 0.18 \\
\hline & & & \\
\hline
\end{tabular}

Considering mass spectroscopy as an analytical technique that specifically identifies the chemical composition of a compound or sample base on the ratio of mass to charge of charged particles. It involves chemical fragmentation of a sample into ions (or charged particles) while measuring two main properties, mass and charge, of the end particles. When the particles are passed through electric and magnetic fields in a mass spectrometer, the mass-charge ratio can be obtained. A mass spectrometer has been designed with three essential modules, each performing a specific function. They are:

1) An ion source: This performs the function of transforming the molecules in a sample into ionized fragments.

2) A mass analyzer: which performs the function of arranging the ions according to their masses using electric and magnetic fields and; 
3) A detector: this measures the value of some indicator quantity thereby providing data essential for calculating the abundances of each ion fragment present in a compound or sample. Mass spectroscopy is particularly important as it can be sued for both qualitative and quantitative measurements including identification of unknown compounds.

Upon dilution of the Mix 525 to 50ng/ul (of each component), the peaks were still detectable and identifiable at that level under mass spectrometer (Figure 17).

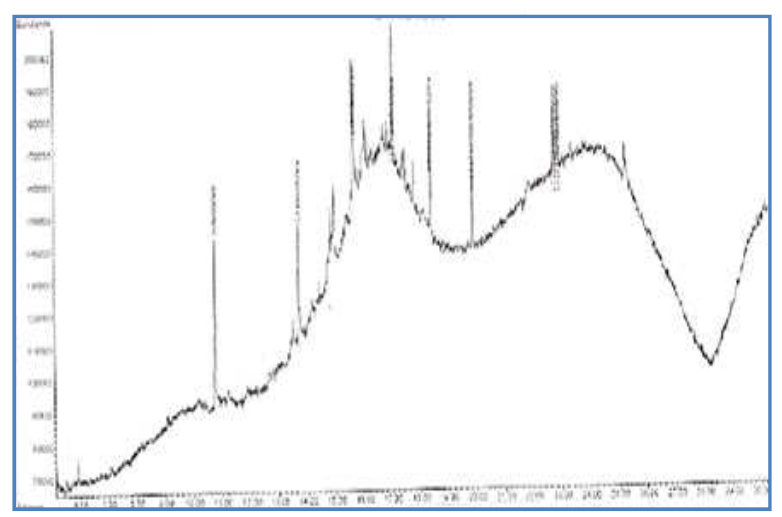

Figure 17: Chromatogram for Mix525 sample

\section{Conclusion}

PCBs are compounds primarily found in transformer oils and capacitors. Recently, these oils are being replaced with PCB-free transformer oils. The SPE procedure as well as the GC/ECD used in this study was efficient enough to produce required result which conforms to the EPA PCB Regulatory Limits. This can be seen in the result obtained by spiking sample A01, which was used as a reference to the other samples. This study did not find any detectable levels of PCBs in the 12 transformer oils sampled from Kebbi state. These results were validated after analysis when it was subsequently discovered that the transformers had recently been refilled with PCB-free oils after clean up.

\section{References}

[1] Bernhard, T. and Petron, S. (2001). Analysis of PCB Congeners vs. Arcolors in Ecological Risk Assessment http://Web.ead.anl.gov/ecorisk/issue/pdf/PCB\%20IssuePape rNavy.pdf Accessed on 12th February 2008.

[2] ANZECC, (1997). Identifying PCB-Containing Capacitors.Australian and New Zealand Environment and Conservation Council. Free encyclopedia Wikipedia http://en.wikipedia.org/wiki/polychlorinatedbishyenylAcces sed on 22nd December, 2007

[3] Shin,S.K. and Kim., T.S.,Kim,J.K., Chung,Y.H.AndChung,R.(2004). Analytical method of polychlorinated biphenyls (PCBs) in transformer oil.Organohalagen Compounds 66.

[4] UNEP,(1999). Guidelines for the identification of PCBs and materials containing PCBs. UNEP Chemicals, 11-13 chemin des Anemones CH-1219 Chatelaine (Geneva), Switzerland.Http://www.chem .unep.ch/pops/pdf/PCBident/ pcbid 1.pdf Accessed on 22ndFebuary 2008.

[5] Kukharchyk, T. I. and Kakareka, S. V.(2008).Polychlorinated biphenyls inventory in Belarus. Journal of environmental Management 88(4).1657-1662

[6] Emmerson, A BVWS.(2002).Technical-Polychlorinatedbiphenyl. And 405-Alive .http ://www.bvws.org.uk/405alive/tech/pcbs.html. Accessed on 22nd November, 2007.

[7] Barbalace. R.C (1995).The chemistry of polychlorinated biphenyls.

http://environmentalchemistry.com/yogi/chemistry /pcb.html.Accessed on 28th November, 2007.

[8] Hill, M.K.(2004) Understanding Environmental Pollution. Cambridge University Press. UK. 2nd edition pg 339-349.

[9] Fiedler, H. (1997). Polychlorinated Biphenyl (PCBS): Uses and Environmental Releases http:www.cheunep.ch/pops/POPs inc/proceedings/cartagena/FIEDLER1 html Accessed on 2nd February 2008.

[10] Ferrario, J., Byrne, C. and Dupuy, A.E(1997). Background contamination by coplanar polychlorinated biphenyl (PCBs) in trace level high resolution gas chromatograph/high resolution mass spectrometry (HRGC/HRMS) analytical methods.Chemosphere 34(11). 2451-2465.

[11] Bunce, N.J. (1994). Environmental Chemistry.Wuerz Publishing Ltd. Canada.2nd edition. Pg 300-305.

[12] Baird, C. (1995). Environmental Chemistry.W.H. Freeman and company. Pg 254-256.

[13] Kim, S., Setford, S.J. and Sain, S (2000). Determination of polychlorinated biphenyl compounds in electrical insulating oils by enzyme immunoassay. Analytical ChimicaActa 422(2).167-77.

[14] Takasuga, T.,Senthilkumar,K., Matsumura,T., Shiozaki, K. and Sakai, S. (2006). Isotope dilution analysis of polychlorinated biphenyls (PCBs) in transformer oil and global commercial PCB formulation by hiresolution gas chromatography-high resolution mass spectrometry.Chemosphere 62(3).469-484.

[15] Takada ,M., Toda,H.andUchida,R .(2001).A new repid method for qualification of PCBs in transformer oil. Chemosphere.43(4-7).455-459.

[16] Finch, S. (1990) Alternative methods of PCB analysis. DEXSIL CORPORATION. www.dexsil.com/uploads/docs/dtr10 01.pdf Accessed on 31st March 2008.

[17] Shin and Kim. (2006) Levels of Polychlorinated Biphenyls(PCBs) in transformer from Korea. Journal of Hazardous Materials 137(3).1514-1522.

[18] Buthe A. and Denker E (1995) .Qualitattive and quantitative determination of PCB congeners by a HT-5 GC columin and an efficient quadrupole Ms. Chemosphere ,30(4). 753-771.

[19] Hoof, P.V. and Hsieh, J. (1996). Analysis of Polychlorinated Biphenyls and Chlorinated Pesticides by Gas Chromatograph 
with Electron Capture Detection. http://www.epa.gov/grtlakes/Immb/methods/sop-501.pdt Accessed on 23rd November, 2007.

[20] Arisawa, K., Takeda, H., and Mikasa, H.(2005). Background exposure to $\mathrm{PCDDs} / \mathrm{PCDF} / \mathrm{PCBs}$ and its potential health effects: a review of epidemiologic studies. The journal of medical investigation 52.10-21.

[21] Bailey, R.A., Clark, H.M., Ferris, J.P., Krause, S., and Strong, R.L. (1978). Chemistry of the environment.Academic press Inc. London Ltd. Pg 157-158.

[22] NTT, (1999).NTT-Technical Bulleting:PCB Testing and Analysis. http://www.nttworldwide.com/pcb.htm. Accessed on 22nd November, 2007.
[23] Huang, P., Gong, S.L., Zhao, T. L., and Barrie, L. A. (2007). GEM/Pops: a global 3-D dynamic model for semi- volatile persistent organic pollutants-part 2: Global transports and budgets of $\backslash$ PCBS. Atmos. Chem. Phys., 7. 4015-4025.

[24] O'Neil, p. (1998).Environmental Chemistry.3rd edition, Thomson Blakie Science Academy and professional.pg 239-240.

[25] Osibanjo,O. (ed.Fielder, H) (2002). Organochlorine in Nigeria and Africa.The hand book of Environmental Chemistry.Persistent organic pollutants.Springer Verlag Berlin Heidelberg Volume 3.321-354.

[26] Wright, j. (2003). Environmental Chemistry.Routledge London. Pg 121-122. 